\title{
CUIDADO FAMILIAL DE RECÉM-NASCIDOS NO DOMICÍLIO: UM ESTUDO DE CASO ETNOGRÁFICO ${ }^{1}$
}

\author{
Julliana de Souza Leandro², Marialda Moreira Christoffel ${ }^{3}$
}

\begin{abstract}
${ }^{1}$ Parte da dissertação - Cuidado familial de recém-nascidos no domicílio: o caso do município de Piraí - Rio de Janeiro. Programa de Pós-graduação da Escola de Enfermagem Anna Nery, 2009.

${ }^{2}$ Mestre em Enfermagem pelo Programa de Pós-graduação da Escola de Enfermagem Anna Nery (EEAN) da Universidade Federal do Rio de Janeiro (UFRJ). Rio de Janeiro, Brasil. E-mail: jullianaleandro@yahoo.com.br

${ }^{3}$ Doutora em Enfermagem. Docente do Departamento Materno-Infantil da EEAN/UFRJ. Rio de Janeiro, Brasil. E-mail: marialdanit@gmail.com
\end{abstract}

\begin{abstract}
RESUMO: O presente estudo de caso etnográfico é um estudo qualitativo que tem como objetivo analisar a dinâmica do cuidado familial com o recém-nascido no domicílio, no município de Piraí-RJ. Os dados foram coletados com 18 familiares de recém-nascidos cadastrados na Unidade de Saúde da Família. Utilizou-se como instrumentos a entrevista aberta, prontuários dos membros das famílias na Estratégia de Saúde da Família e a observação participante. Da análise temática emergiram três categorias: dimensão psíquica do cuidado familial com o recém-nascido no domicílio; dimensão biosociocultural do cuidado familial com o recém-nascido; e o cuidado familial com o recém-nascido e sua interface com o parto e o puerpério. Neste estudo, as dimensões psíquicas e biossocioculturais do cuidado familial estão presentes em diferentes cenários da atenção à saúde do recém-nascido. Conclui-se que, para cuidar do recém-nascido e de sua família em sua integralidade, é preciso repensar as culturas que se entrelaçam no cuidado familial e no cuidado profissional.
\end{abstract}

DESCRITORES: Família. Recém-nascido. Cuidados de enfermagem.

\section{FAMILY HOME CARE FOR NEWBORNS: AN ETHNOGRAPHIC CASE STUDY}

\begin{abstract}
The present ethnographic case study is a qualitative study whose purpose is to analyze the dynamics of home family care given to newborns in Pirai, RJ, Brazil. Data was collected from 18 families with newborns registered at a Family Health Unit. Data collection instruments included open interviews, records of family members at the Family Health Strategy, and participant observation. Thematic analysis revealed three categories: the psychological dimension of home family care for newborns; the bio-socio-cultural dimension of family care for newborns, and family care for newborns and their interface with delivery and the postpartum period. In this study, the psychological and bio-socio-cultural dimensions of familial care are present in different newborn care scenarios. We conclude that in order to care for newborns and their families in their entireties, it is necessary to rethink the cultures entwined in family care and professional care.
\end{abstract}

DESCRIPTORS: Family. Newborn. Nursing care.

\section{EL CUIDADO FAMILIAR DE LOS RECIÉN NACIDOS EN EL HOGAR: UN ESTUDIO DE CASO ETNOGRAFICO}

\begin{abstract}
RESUMEN: El presente estudio de caso etnográfico es un estudio cualitativo con el objetivo de analizar la dinámica de la atención en el hogar de las familias de los recién nacidos en la ciudad de Piraí-RJ, Brasil. Se recogieron datos de 18 familias de los recién nacidos matriculados en la Unidad de Salud Familiar. Se emplearon los siguientes instrumentos: la entrevista no estructurada, los registros de los miembros de las familias en la Estrategia de Salud Familiar y la observación participante. El análisis temático reveló tres categorías: la dimensión psicológica del cuidado familiar al recién nacido en el hogar, la dimensión biosociocultural del cuidado familiar al recién nacido; y el cuidado familiar a los recién nacidos y su interfaz con el parto y el puerperio. En este estudio las dimensiones psicológicas y biosocioculturales de la atención familiar están presentes en diferentes espacios de la atención de la salud del recién nacido. Se concluye que en el cuidado de los recién nacidos y de la familia en su totalidad es necesario repensar las culturas que se entrelazan con el cuidado familiar y el cuidado profesional.
\end{abstract}

DESCRIPTORES: Familia. Recién nacido. Atención de enfermería. 


\section{INTRODUÇÃO}

Os programas e políticas de saúde infantil ${ }^{1-5}$ só recentemente começaram a incidir sobre os problemas específicos dos recém-nascidos, pois além da mortalidade, preocupa a falta de continuidade do cuidado prestado no hospital, no cuidado observado no domicílio e na comunidade, visando à qualidade de vida das crianças, para possibilitar que cresçam e desenvolvam harmoniosamente todo seu potencial. É nesse período que mais ocorrem situações que envolvem mãe e bebê, como as dificuldades na amamentação (seja por problemas com a pega e a posição, seja pelas crenças populares que influenciam essa prática), os cuidados com o coto umbilical e a higiene.

A importância de se valorizar o cuidado com o recém-nascido, no contexto da família e da comunidade, principalmente no local onde vivem, revela que o cuidado da equipe de saúde junto à família e à comunidade, particularmente após o nascimento, é capaz de prevenir mortes neonatais, em números que vão de $18 \%$ a $37 \%$, sobretudo em contextos com elevada mortalidade e sistemas de saúde enfraquecidos. ${ }^{4-5} \mathrm{O}$ cuidado engloba a educação em saúde, mobilização e engajamento comunitário para estimular as melhores práticas pré-natais e pós-natais, a gestão de casos de doenças na comunidade (como a pneumonia), apoio e incentivo à amamentação e à imunização e a mobilização comunitária por serviços de qualidade., ${ }^{2,-5}$

A criança recém-nascida é vulnerável por sua condição de dependência total do cuidado de adultos. Nasce no hospital e recebe cuidado tanto da equipe de enfermagem (cuidado profissional), como da mãe e da família (cuidado familial), e quando segue para o domicílio, continua recebendo cuidados, geralmente orientados por profissionais de saúde e por membros da família e da comunidade, que constituem sua rede de suporte social. ${ }^{3}$

O cuidado familial é um conceito em construção, uma proposta de sistematização conceitual do que representa o processo apreendido e construído pela família, definido a partir da cultura familial, das interações sociais intrafamiliares e extrafamiliares, ao longo do processo de vida da família, e nas diferentes etapas de vida do ser humano. ${ }^{3}$

Compreender a lógica interna da família, seus modos de viver, conviver e cuidar indica um paradigma emergente na saúde, que convive atualmente como o paradigma dominante, centrado na doença, na cura e no hospital. Esse paradigma emergente aponta para a valorização do saber informal e do cuidado que a família realiza e, ainda, para a família como objeto de cuidado e investigação.

Nesse sentido, é imprescindível que esse cuidado seja congruente com o ambiente socioeconômico e cultural da família e da comunidade. O cuidado ainda é prescritivo, centrado na patologia e em procedimentos do contexto hospitalar, e os profissionais de saúde, principalmente os da enfermagem, desenvolvem esse cuidado voltados para o modelo tecnocrático. Existe, portanto, uma lacuna na literatura referente ao cuidado da família no cenário do domicílio e à necessidade de estudos na perspectiva de superação do modelo atual de atenção à saúde. ${ }^{3}$

Todas essas questões refletem a importância e a necessidade constante de suporte técnico, orientação e acompanhamento por parte de profissionais de saúde - principalmente da enfermagem - para os cuidados prestados por familiares ao recém-nascido.

Como enfermeira assistencial da área hospitalar, prestes a fazer uma mudança do meu lugar social, para atuar na Equipe Saúde da Família (ESF), despertei para alguns desafios: o de cuidar do recém-nascido no contexto familiar e na comunidade, já que a Estratégia de Saúde da Família tem como prioridade a família, entendida a partir do ambiente onde vive e do modo como vive; e o estabelecimento de vínculo para a co-responsabilização de profissionais de saúde e da população, no sentido da promoção da saúde e da prevenção de doenças. ${ }^{4}$

Este estudo, voltado para o cuidado familial com o recém-nascido no domicílio, busca compreender o contexto em que ele está inserido, numa perspectiva sociocultural. A família é um grupo social que deve ser compreendido como unidade dotada de dinamismo próprio e, nesse contexto, a saúde do recém-nascido está vinculado às condições maternas e ao atendimento prestado ao recém-nascido na primeira semana de vida. ${ }^{1,4-5}$ Diante do exposto, o presente estudo tem como objetivo analisar a dinâmica do cuidado familial com o recém-nascido.

\section{METODOLOGIA}

O presente estudo de caso etnográfico trata-se de uma pesquisa qualitativa. O estudo de caso etnográfico é caracterizado por enfatizar o conhecimento do singular e preencher os requisitos da etnografia, possibilitando visões profundas, amplas e integradas de uma unidade social complexa, 
composta de múltiplas variáveis, e acrescentando

a dimensão sociocultural à investigação. ${ }^{6-7}$

Esse tipo de estudo surgiu recentemente na literatura da área de Educação, a partir da década de 1960, como uma proposta de adaptação da etnografia ao estudo de caso educacional, que não se configurava em etnografia no seu sentido estrito, mas em estudo do tipo etnográfico, com a perspectiva de acrescentar as dimensões existenciais, simbólicas e culturais. ${ }^{6}$

O presente estudo foi desenvolvido na Unidade de Saúde da Família da Ponte das Laranjeiras, no município de Piraí, que abrange área rural e urbana. O município de Piraí faz parte de uma região chamada Vale do Médio Paraíba, no Estado do Rio de Janeiro. Participaram do estudo quatro famílias constituídas de 18 familiares de recém-nascidos (0 a 28 dias), sendo quatro mães, quatro avós, dois pais, um avô, uma prima e seis tias.

A coleta de dados foi realizada com as técnicas de observação participante, entrevista aberta, consulta às fichas de cadastramento das famílias na ESF e aos prontuários dos membros das famílias. Os prontuários foram selecionados a partir do momento em que a equipe de saúde da família identificava as mulheres grávidas e realizava o acompanhamento durante todo o ciclo gravídico-puerperal. As entrevistas eram agendadas no momento das duas últimas consultas realizadas no pré-natal, na unidade de Estratégia de Saúde da Família.

Os dados foram coletados no período de Janeiro a Abril de 2009, nos domicílios. Na observação participante ocorreu a interação do pesquisador com os interlocutores no espaço social da pesquisa, com perguntas, sempre que necessário, sobre o que estava sendo observado. O pesquisador se colocava portanto como observador da situação para colher dados e compreender o contexto da pesquisa, vinculando os fatos às suas representações. ${ }^{6-7}$ A observação participante se desenvolveu por meio de três a quatro visitas aos domicílios, durante um período de cinco meses, registradas em diário de campo.

A inserção da pesquisadora no campo de pesquisa gerou um diário de campo e, por meio dessa técnica, foi possível observar o cotidiano das puérperas e o cuidado realizado com o recém-nascido, bem como os comportamentos e as situações com que elas se defrontam no cotidiano, os ambientes, a relação e os diálogos com os familiares e os instrumentos ou objetos utilizados no cuidado com o recém-nascido. Procurou-se, assim, aproximar interpretações e fatos observados.
As observações foram complementadas com entrevistas abertas gravadas e transcritas. A entrevista do tipo aberta durou em torno de uma hora e meia e abordou o processo reprodutivo, particularmente a descrição de experiências, os cuidados com amamentação, banho e higiene, desenvolvimento, hábitos e rotinas, percepções e valores diante das dificuldades e de todas as informações sobre o cuidado familial com o recém-nascido.

As famílias foram identificadas por pseudônimos: Família 1 - Flores; Família 2 - Frutas; família 3 - Ervas e Plantas e Família 4 - Árvores. Cada membro da família recebeu um nome fictício referente aos pseudônimos das famílias. As puérperas foram identificadas como Papoula, 25 anos; Tâmara, 17 anos; Camomila, 37 anos; Garapa, 30 anos. Foram realizadas três visitas domiciliares para as famílias 1 (Flores), 3 (Ervas e Plantas) e 4 (Árvores) e quatro visitas para a família 2 (Frutas).

Todos os aspectos éticos foram considerados durante o processo da pesquisa, de acordo com a Resolução 196/96. A pesquisa recebeu o número 238/08 no cadastro do Comitê de Ética em Pesquisa da Secretaria Municipal de Saúde do Rio de Janeiro.

Para o tratamento dos dados, utilizou-se a análise temática de conteúdo, com a intenção de evidenciar qualitativamente os significados emergentes do material analisado. ${ }^{6-7}$ Esse processo contemplou os dados empíricos em suas particularidades, articulados com os objetivos da pesquisa, aos pressupostos adotados e à bibliografia consultada.

Os resultados, neste artigo, são apresentados e debatidos através de três categorias: (a) dimensão psíquica do cuidado familial com o recém-nascido no domicílio; (b) dimensão biossociocultural do cuidado familial com o recém-nascido, que é representada por duas subcategorias (b1) o universo de significados da família e os cuidados com o recém-nascido na primeira semana de vida; e (b2) o universo de significados da família e as relações com o sistema profissional de cuidado durante o aleitamento materno, e (c) cuidado familial ao recém-nascido e sua interface com o parto e o puerpério.

\section{APRESENTAÇÃO E DISCUSSÃO DOS DADOS}

\section{Dimensão psíquica do cuidado familial com o recém-nascido no domicílio}

A fragilidade do corpo do recém-nascido é apontada por todos os familiares. Tal fragilidade 
é associada principalmente à presença do coto umbilical e à dificuldade de sustentação do corpo "molinho", que causam insegurança e dificuldade na hora de realizar cuidados de higiene e pegar no colo. Os sentimentos dos familiares em relação ao cuidado do recém-nascido no domicílio são mistos de preocupação, impaciência, insegurança e responsabilidade. Os relatos apresentam tais sentimentos:

[...] eu não dou [o banho] porque eu tenho medo do umbigo [...] (Mãe Tâmara).

[...] eu tenho medo [de dar banho] por causa do umbigo, de machucar o umbigo dela [...] medo de esbarrar no umbigo e sair rasgando (Mãe Camomila).

[...] muito molinho, assim, é ruim de segurar. Até pegar no colo é chato. Quando tiver maior pode jogar para cima [risos]. Por causa do umbiguinho também, quem não for muito ajeitado para pegar, pode também [...] (Pai Umbu).

Muitas vezes esse cuidado é naturalmente assumido pelos familiares, sem que a mãe solicite, modificando a rotina e a dinâmica familiar. Nota-se que a pessoa que passa a realizar os cuidados é a pessoa com mais experiência, tradicionalmente responsável pelo cuidado dos recém-nascidos na família A participação do pai, de um familiar ou de outra pessoa significativa nas consultas pré-natais, nas atividades educativas em grupo e nas visitas domiciliares é essencial para que o vínculo com profissional se estabeleça e permita maior possibilidade de diálogo sobre sentimentos e preocupações trazidos com a chegada do recém-nascido. Para tanto, é preciso mudar o foco da atenção pré-natal do profissional e da gestante para a família, valorizando-a e incentivando sua presença. ${ }^{8-11}$

O cuidado representado como dedicação está associado à preocupação e ao zelo, o que pode ser identificado na fala da Avó Margarida quando ela diz que seu sono está prejudicado porque é preciso olhar o recém-nascido. $\mathrm{O}$ afeto pela primeira neta também pode ser percebido na fala que se segue. A avó Margarida destaca que ela e o Avô Monsenhor "já estão de idade", e precisam se fazer presentes para a neta:

[...] a gente tem cuidado [...]. Esses dias nem tenho dormido direito, só olhando ela. É a primeira netinha, a gente tem que carinhar mais ela, A gente já está de idade também [...] (Avó Margarida).

O cuidado também é manifestado no desejo de querer estar próximo, pegar no colo, conversar e cantar, como podemos perceber nos depoimentos a seguir.
[...] tem que acostumar, tem que pegar? [...] Agora de noite ele [o pai] já pega ela, hoje já veio ver ela. Hoje ele já veio umas três vezes aqui (Avó Margarida).

[...] pega [a tia, irmã da mãe], nunca mais larga! Só quando vai embora. Deita ela ali e fica, [...] vira, paparica bem ela. Nunca vi criança tão [...] conversa com ela também. Acho que se ela morasse perto não ia sair daqui de casa [...] (Mãe Camomila, Avó Macela, Irmã Jupeba).

A presença é considerada um atributo do cuidado familial. É associada à solidariedade entre os membros da família e é fundamental para que o ser humano possa crescer, desenvolver-se e realizar-se integralmente. ${ }^{3,8-9}$ Essa presença é essencial nos primeiros anos de vida e no apoio a puérpera no cuidado do recém-nascido.

As manifestações de carinho dos familiares representam, assim como a conversa, segurança emocional e social para o recém-nascido no grupo familiar. Representam, ainda, a sua inclusão cultural, que ocorre à medida que o vínculo se estabelece na convivência familiar. ${ }^{8-10} \mathrm{O}$ contato precoce e intenso entre os pais e os bebês garante benefícios importantes, como a promoção do vínculo precoce, o crescimento e desenvolvimento neurológico do recém-nascido e a regulamentação

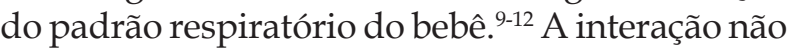
ocorre apenas entre a mãe e o recém-nascido, mas entre a família e o recém-nascido (irmã, avó, pai e tios, ou seja, as pessoas que residem na mesma casa ou que têm um contato próximo e são significativas também passam por esse processo de reconhecimento e interação que é importante para a convivência em família e promoção de vida). A família não é formada apenas por pessoas, mas também por uma teia de relações. A presença, as manifestações de afeto, à vontade de estar junto, os gestos de carinho e de cuidado formam e fortalecem vínculos que conectam as teias de relações e aproximam os familiares emocionalmente., ${ }^{3,10-12}$

O cuidado com a saúde da criança e suas famílias é obtido mediante o diálogo, com articulação entre os saberes técnicos e os saberes práticos. O cuidar deve ultrapassar as técnicas e a tecnologia, ter uma visão ampla do que está posto ao redor, interagir com o ser cuidado no sentido de fugir da objetivação que, por vezes, aniquila a identidade do sujeito a ser cuidado, vendo-o apenas como um receptor de uma ação interventiva. O seguimento da saúde do recém-nascido e sua família devem ocorrer nos serviços de atenção primária disponíveis para essas famílias, tendo início na primeira semana em que estão em casa após a 
alta hospitalar, pois este é um período crítico para adaptação da criança em casa, bem como dos pais à rotina de cuidar do recém-nascido no domicílio.

Os depoimentos apontam os cuidados dos familiares com relação à dor e ao choro do recém-nascido, bem como a forma com que estes interferem nas relações familiares. Para os familiares, o choro do recém-nascido está associado à fome, a diferentes tipos de dor, às eliminações vesico-intestinais e até mesmo à fragilidade do recém-nascido e do lactente. Uma avó e uma mãe reconhecem a cólica através de movimentos corporais como "mexer muito com as pernas", "encolher", "retorcer o pezinho" e, ainda, através do choro incessante e intenso, como vemos nos depoimentos:

[...] até três meses a criança chora muito né? [...] A gente cuida dela direitinho [risos], agora não sei se ela tá sentindo dor na barriga ou dor de ouvido, porque tem hora que chora muito, grita mesmo [...]. Muito alto mesmo [...]. A perninha, mexe muito com as pernas, se encolhe todinha [...] (Avó Margarida).

[...] Ele estava chorando, quando aplicou a injeção [vacina], parou. Quando furou no pezinho parou de chorar também. Só chorou na hora que apertou, quando apertou o pezinho, chorou. Parece que gosta de sentir dor [...] (Pai Umbu).

Uma das causas mais comuns de choro, no recém-nascido, é a chamada cólica. "O choro é, de todos os padrões de comportamento pré-verbais, $\mathrm{o}$ que mais chama a atenção dos pais". ${ }^{13: 34}$ A cólica é um problema que afeta de $9 \%$ a 13\% dos lactentes e há divergências entre os autores quanto à causa e uma lacuna na pesquisa científica em relação ao seu tratamento. Embora criticada, a definição clínica mais aceita na literatura é a que descreve esta síndrome como paroxismos de irritabilidade, agitação ou choro, durante cerca de três horas por dia, geralmente no fim da tarde ou início da noite, pelo menos três dias por semana, e que desaparecem aos três meses de vida. O choro é súbito e inconsolável, podendo ser acompanhado por vermelhidão e movimentos corporais como o esticamento de pernas e a flexão dos joelhos com pressão das coxas sobre o abdome. ${ }^{13}$

Como se vê na fala da Avó Embaúba, o choro provoca nas pessoas diferentes reações como preocupação, "nervoso" e sentimento de impotência por desconhecimento de seu motivo; além de "desespero" e "pena". O choro para algumas mães e familiares significa que o seu sono será prejudicado.

[...] ela começa a chorar, me dá nervoso, eu fico nervosa, que não para de chorar nunca [...]. Agora ela não tá mais chorando, só quando ela está com cólica. Desde ontem ou anteontem que ela não tá reclamando muito, só pra mamar [...] (Irmã Jupeba).

As mães percebem a cólica do recém-nascido a partir de alterações comportamentais como choro insistente, por exemplo. Sentem-se incapacitadas, angustiadas e cansadas; associam a cólica a intercorrências na gravidez e no parto, inexperiência em cuidar de bebês, alimentação inadequada. Para aliviar o desconforto, utilizam manobras físicas e chás, além de procurar a ajuda dos serviços de saúde, de familiares e até de Deus. ${ }^{13}$

\section{Dimensão biossociocultural do cuidado familial com recém-nascido no domicílio}

A dimensão biossociocultural no cuidado com o recém-nascido no domicílio foi analisada a partir de duas subcategorias. A primeira considera o universo de significados da família e os cuidados com o recém-nascido na primeira semana de vida.

Essa subcategoria aborda as práticas realizadas por mãe, pai e familiares para os cuidados relacionados à higiene do recém-nascido, principalmente no que se refere ao banho e ao cuidado com o coto umbilical. A prática do banho do recém-nascido é descrita em um passo-a-passo, como se pode exemplificar no depoimento abaixo:

[...] ponho dentro da banheira. Primeiro eu jogo a água no corpinho dela [...]. Muita gente joga água e benze assim, quando cruza a água, os antigos. Muitas mães, minha avó fazia isso, colocava um pouquinho de água na boca, isso eu não faço, só benzo ali. Joga a água e cruza no corpo da criança, a água da banheira. Aí ensaboa o rostinho, tudo assim, a cabeça [...] vai jogando água pra não deixar cair no ouvido. Ensaboa bem ensaboadinho, depois joga bastante água pra tirar o sabão. $O$ umbigo que eu não molho muito, não mexo muito nele não. Uma coisa que eu tenho que arrumar [...] não é esponja não, é tipo uma esponjinha pra poder ensaboar ela, pra não passar só a mão (Avó Macela).

Observa-se que essa prática habitual de dar banho está cercada de crenças passadas de geração em geração (como o ato de benzer, ou cruzar a água no corpo da criança). Outras práticas dos "mais antigos" não são seguidas (como o ato de colocar um pouco da água do banho na boca do bebê). Outras crenças presentes dizem respeito a não passar a mão diretamente no corpo da criança e a não mexer muito no umbigo do recém-nascido.

As famílias desenvolvem rituais de cuidado que são as ações com alto teor simbólico, desenvolvidas durante o "rito de passagem" ocorrido 
com o nascimento, com significados impressos a partir do contexto cultural. ${ }^{3,14}$

A segunda subcategoria considera o universo de significados da família e as relações com o sistema profissional de cuidado durante o aleitamento materno.

O aleitamento materno é um ato ao mesmo tempo biológico, histórico, social e cultural. As crenças e os tabus influenciam sua prática, interferindo na construção de uma herança sociocultural e conferindo diferentes significados ao processo de amamentação, tanto para a mulher e seus familiares como para os profissionais de saúde. O aleitamento materno é um dos aspectos do cuidado familial que merece destaque, pois diz respeito à alimentação do recém-nascido como um processo que ultrapassa os limites biológicos e envolve aspectos socioculturais e uma rede de relações entre família e profissionais de saúde. As crenças sobre o "leite fraco" e as práticas relacionadas à amamentação se fazem presentes. ${ }^{15-16}$

O Ministério da Saúde ${ }^{16}$ propõe um trabalho articulado, com foco na Atenção Básica, integrando-se às demais redes, a saber, Iniciativa Hospital Amigo da Criança, Iniciativa Unidade Básica Amiga da Mulher, Bancos de Leite, e visando a aumentar a resolutividade de ações através dos pilares de educação crítico-reflexiva e educação permanente e do conceito de amamentação como ato híbrido, que envolve natureza e cultura, valorizando o papel da família nesse processo. Torna-se importante abordar, discutir e refletir, juntamente com a sociedade, especialmente com as mulheres e familiares, as questões culturais que permeiam a prática do aleitamento materno. No depoimento abaixo estão representadas as dificuldades encontradas na amamentação.

[...] de manhã ela acorda, Papoula dá mama, se não ela [bebê] chora muito [...] depois eu dou o banho, depois ela mama de novo. Também tem que dar os dois peitos e assim mesmo não dá [...] ainda continua chorando [...] aí vai indo, vai indo, aí que dorme. Eu dei de mamar a ela até quatro anos. Tinha que botar a fralda senão encharcava o outro. Ela mamava em um e o outro tava espirrando. Por isso eu acho que ela tem pouco leite, ela é difícil vazar no outro peito. Quandoé assim, não tem muito [...] (Avó Margarida).

[...] isso a mãe não escondeu não. Está mamando na chuquinha mesmo [...] (Mãe Papoula).

O desafio atual para os profissionais de saúde é compreender o processo da amamentação, que vai além das alterações hormonais e fisiológicas, ou das considerações sobre a posição e a pega. A amamentação deve ser compreendida não apenas em seu aspecto biológico, mas também em relação ao seu condicionamento sociocultural. Desconstruir os significados que desestimulam as mulheres a amamentar e que estão arraigados em nossa cultura é um processo complexo e demorado, pois tais significados, hoje, não nos servem, mas fizeram parte da vida em outros momentos. ${ }^{15}$

[...] ele mamava um pouquinho, puxava aquela aguinha que vem primeiro, muito pouquinho, aí acho que ele puxava, cansava, ai dormia. Aí todo mundo achava que ele tinha se alimentado, aí quando ele acordava, acordava fazendo o maior escândalo, com bastante fome porque não estava se alimentando [...] (Pai Umbu).

A adaptação ao papel materno ou paterno e o desempenho dos pais estão envoltos no aspecto cultural das famílias; o envolvimento dos membros da família e/ou dos profissionais de saúde pode significar apoio ou responsabilização, quando a mãe está inapta a realizar os cuidados com o filho. ${ }^{14-15}$

[...] o que importa é que esta mamando leite do peito, não importa como. E ela quis que eu ajudasse na amamentação [...] (Avó Imbaúba).

A prática do aleitamento materno está sendo estimulada com o intuito de aumentar a prevalência da amamentação exclusiva até o sexto mês, momento em que devem ser introduzidos alimentos complementares na dieta da criança. Nesta luta pela lactação natural é imprescindível a participação de todos e o incentivo direto de familiares, com destaque para as avós maternas e paternas, que estão presentes em quase todos os nascimentos e participam da construção de uma cultura. ${ }^{15}$

[...] por fim, até a equipe da ESF falou, se está tomando leite do peito, só do peito, deixa mamar. O negócio é dar leite do peito. Eu não estou dando outra coisa pra ele, não estou mesmo [...] (Mãe Garapa).

O papel da Equipe de Saúde da Família pode ser destacado como importante para a prática do aleitamento materno. Além do acompanhamento com visitas domiciliares durante o pré-natal, a visita domiciliar na primeira semana de vida do recém-nascido em casa é uma estratégia que pode facilitar a prática da amamentação. Além disso, os profissionais devem apoiar a família, reconhecendo que a amamentação é importante para a saúde de todos, podendo ajudar no alívio de afazeres domésticos, sem esquecer que o ato de amamentar é um momento sensível de contato entre a mãe e o bebê. A visita domiciliar é uma ferramenta que pode ser utilizada para estabelecer uma aproxi- 
mação entre famílias e profissionais de saúde na ESF. Ela é hoje considerada um dos instrumentos utilizados nas intervenções de enfermagem no cuidado familial. ${ }^{8,15}$

\section{O cuidado familial com o recém-nascido e sua interface com o parto e o puerpério}

Essa categoria apresenta o cuidado familial com recém-nascido e sua interface com o parto e o puerpério. As vivências e experiências das puérperas e familiares durante o parto foram marcantes neste estudo. As falas demonstram a vivência do parto hospitalar e a manifestação do cuidado familial como presença.

[...] foi difícil, mas estava na hora, eu estava tendo contração, aí eu cheguei na sala de parto e eu não tive mais contração, ela já estava encaixada, aí foi difícil. Eu levei muito ponto. Ela já tava encaixada, não tinha como fazer nada, eu tive que fazer força. Pra nascer foi rápido, o problema todo, demorou pra me costurar, porque me cortou toda [...] levou umas duas horas, não é mãe?! Costurando-me. A mãe tava lá, mas na hora que fui entrar pra ter ela, não deixaram a mãe entrar não, mas ela tava lá. Depois que ela nasceu, que botou ela em cima de mim, quando estava me costurando, aí eu sentia muita dor, aí chamaram ela pra segurar, aí ela ficou lá [...] (Mãe Papoula).

A humanização do parto e do nascimento exige de todos os atores envolvidos com a atenção à saúde esforços para abolir condutas intempestivas e agressivas, tanto para a mulher como para o recém-nascido, garantindo assistência segura e de qualidade. Além disso, os vínculos afetivos devem ser fortalecidos logo após o nascimento. ${ }^{1-2,4}$ A presença do acompanhante escolhido pela mulher no momento do parto deixa de ser uma concessão para se tornar um direito das mulheres e das famílias. ${ }^{2}$

[...] eu tava lá [no momento do parto], minha filha também chegou correndo, deixou o filho pela metade do caminho, eu quero ver, eu quero ver, Jupeba falou, já nasceu [...]. Foi até engraçado, foi uma das coisas que eu podia até ter gravado [...] (Avó Macela).

Em relação à puérpera, os cuidados mais enfatizados são os de proteção do resguardo, que coloca mães e recém-nascidos em condições vulneráveis, em termos físicos e simbólicos. ${ }^{14} \mathrm{O}$ cuidado familial com a mulher nesse período está relacionado às atividades domésticas corriqueiras, como alimentação e higiene, entre outras. Isso ajuda a Equipe de Saúde da Família a compreender a teia de significados que envolve o processo saúde-doença da mulher e do recém-nascido no ciclo gravídico-puerperal.

[...] resguardo quebrado chega a ficar doido [...] diz que gravidez não é doença, é ruim de não ser 40 dias [...]. Escrever, ler, costurar, nada disso. Eu falei pra ela, não tem necessidade nenhuma de ela varrer casa, lavar roupa, fazer comida, não tem necessidade nenhuma disso. Depois que passar [...]. Porque sempre na família a gente tem muita preocupação, tem muita desavença, $e$ isso tudo ajuda né [...] quer dizer, se a pessoa não tiver um pouco assim, de cuidado. Eu falo com a filha dela, sua mãe não pode nem escrever, nem costurar. Eu nunca costurei. Se tiver os quarenta dias para guardar, porque não guarda os quarenta dias? (Avó Macela).

O cuidado assume especificidades para atender às necessidades e às características individuais da puérpera, do recém-nascido e da família que acompanha e avalia o estado de saúde de seus membros e toma decisões quanto aos caminhos que deve seguir em caso de queixas e mal-estar. Nesse sentido, é possível afirmar que o cuidado familial com o recém-nascido é um processo apreendido e construído pela família, fortalecido pela rede de suporte social e que exige transformações dos profissionais de saúde em relação aos seus cuidados. É necessário utilizar uma abordagem baseada na integralidade do cuidado e na interação entre sujeitos, famílias e profissionais de saúde, mediada por uma relação de confiança e pelo estabelecimento de um processo participativo.

\section{CONSIDERAÇOES FINAIS}

Neste estudo, as dimensões psíquicas e biossocioculturais do cuidado familial estão presentes em diferentes cenários da atenção à saúde do recém-nascido, desde a gestação até o momento do parto, e durante o puerpério, vistos como um todo complexo. Logo, um sistema de saúde que se propõe a cuidar do recém-nascido e de sua família em sua integralidade, deve ir ao encontro de suas necessidades em diferentes dimensões e cenários de atenção à saúde.

As práticas familiares proporcionaram meios para que se alcançassem os significados do cuidado familial (explícito ou implícito) com o recém-nascido no domicilio e em alguns momentos latentes. Com isso, os profissionais que atuam na Estratégia de Saúde da Família puderam refletir sobre sua prática profissional. Muitas vezes esse cuidado se manifesta naturalmente entre familiares, sem que a mulher o solicite, modificando a rotina e a dinâmica familiar. 
Nota-se que o familiar a realizar os cuidados é a pessoa com mais experiência, tradicionalmente responsável pelo cuidado de recém-nascidos na família. O acompanhamento do recém-nascido pelos profissionais de saúde deve ser contínuo e deve iniciar precocemente, do nascimento aos primeiros anos de vida. Sugere-se que as visitas domiciliares sejam semanais, o que pode minimizar as dificuldades características desse período, facilitando a adaptação e o rearranjo do funcionamento familiar e contribuindo para o melhor desenvolvimento da criança.

O cuidado familial permite pensar de forma integrada as relações familiares no cuidado do recém-nascido no domicílio. Torna-se essencial que os profissionais de saúde possam ouvir, identificar problemas, compreender, acolher e aconselhar, sem perder de vista que aconselhar não é impor o que se deve fazer, mas apoiar e orientar de forma clara para tentar ajudar nas decisões que precisam ser tomadas. As orientações fornecidas pelos profissionais de saúde só fazem sentido quando atendem às necessidades reais das famílias e têm significados dentro de seu contexto social, econômico e cultural em que elas se inserem.

Recomenda-se que espaços de educação em saúde já existentes nas unidades de saúde da família abram espaços para essa aboradagem e fomentem a discussão sobre a família e o cuidado familial. Parece-nos necessário ainda que o processo de formação do profissional de saúde seja mais articulado com a lógica da saúde da família, não apenas como modelo de atenção básica, mas como um novo paradigma que vai além do paradigma atualmente em dominação

\section{REFERÊNCIAS}

1. Ministério da Saúde (BR). Secretaria de Atenção à Saúde. Departamento de Ações Programáticas Estratégicas. Agenda de compromissos para a saúde integral da criança e redução da mortalidade infantil. Brasília (DF): MS; 2004.

2. Ministério da Saúde (BR). Secretaria de Atenção à Saúde. Departamento de Ações Programáticas Estratégicas. Pacto nacional pela redução da mortalidade materna e neonatal. Brasília (DF): MS; 2004.

3. Elsen I. Cuidado familial: uma proposta inicial de sistematização conceitual. In: Elsen I, Marcon SS, Santos MR. O viver em família e sua interface com a saúde e a doença. Maringá (PR): Eduem; 2004.

4. Tuon RA, Machado FMSB, Furlan VA. Vigilância em recém-nascido de risco: parceria entre atenção terciária e Unidades de Saúde da Família [online]. In: Ministério da Saúde (BR). III Concurso Nacional de Experiências em Saúde da Família: trabalhos premiados. Brasília (DF): MS; 2008. p.49. Disponível em: http://189.28.128.100/dab/docs/publicacoes/ geral/livro_premiados_internet.pdf

5. Organização Mundial de Saúde (OMS). Departamento de saúde e desenvolvimento da criança e do adolescente. Sobrevivência neonatal: saúde dos recém-nascidos, a chave para a sobrevivência da criança [online]. 2005 [acesso 2009 Out 23]. Disponível: http://www.who.int/ child_adolescent_health/documents/pdfs/lancet_ neonatal_survival_series_pr.pdf.

6. Sarmento MJ. O estudo de caso etnográfico em educação. In: Zago N, Carvalho MP, Vilela RA, Organizadores. Itinerários da pesquisa: perspectivas qualitativas em sociologia da educação. Rio de Janeiro (RJ): DP\&A; 2003.

7. Oliveira RC. O trabalho do antropólogo: olhar, ouvir, escrever. $3^{\mathrm{a}}$ ed. São Paulo (SP): Unesp. 2006.

8. Mandú ENT, Gaíva MAM, Silva MA, Silva AMN. Visita domiciliária sob o olhar de usuários do programa saúde da família. Texto Contexto Enferm 2008 Jan-Mar; 17(1):131-40.

9. Bergamashi SFF. Vivência da puérpera-adolescente no cuidado do recém-nascido no domicílio. Rev Esc Enferm USP. 2008 Set. 42(3):454-60.

10. Zagoneli IPS, Martins M, Pereira KF, Athayde J. $O$ cuidado humano diante da transição ao papel materno: vivências no puerpério. Revi Eletr Enf [online]. 2003 [acesso 2009 Ago 24]; 5(2):24-32. Disponível em www.fen.ufg.br/revista/revista5_2/ pdf/materno.pdf.

11. Bustamante V, Trad LAB. Cuidando da saúde de crianças pequenas no contexto familiar: um estudo etnográfico com famílias das camadas populares. Ciênc Saúde Coletiva [online]. 2007 [acesso 2009 Jun 10]; 12(5):1175-84. Disponivel em: http:/ / www.scielosp.org/scielo.php?pid=S1413$81232007000500014 \&$ script $=$ sci_arttext

12. Bustamante V, Trad LAB. Participação paterna no cuidado de crianças pequenas: um estudo etnográfico com famílias de camadas populares. Cad Saúde Pública [online]. 2005 [acesso 2009 Mai 30]; 21(6):1865-74. Disponível em: http://www.scielo. $\mathrm{br} / \mathrm{pdf} / \mathrm{csp} / \mathrm{v} 21 \mathrm{n} 6 / 26 . \mathrm{pdf}$

13. Saavedra MAL, Costa JSDS, Garcia G, Horta BL, Tomas E, Mendonça R. Incidência de cólica no lactente e fatores associados: um estudo de coorte. J Pediatr [online]. 2003 [acesso 2008 Abr 10]; 79(2):115-22. Disponível em: http:// www.jped.com.br/conteudo/port_resumo. asp? varArtigo $=962 \&$ cod $=54$.

14. Monticelli M. Rituais de vida e de cuidado com o nascimento e parto. In: Elsen I, Marcon SS, Silva 
MR. O viver em família e sua interface com a saúde e a doença. Maringá (PR): Eduem, 2004. p. 127-36.

15. Teixeira MA, Nitschke RG, Gasperi P, Siedle MJ. Significados de avós sobre a prática do aleitamento materno no cotidiano familiar: a cultura do querer- poder amamentar. Texto Contexto Enferm. 2006 Jan-Mar; 15(1):98-106.

16. Ministério da Saúde (BR). Rede Amamenta Brasil. Caderno do Tutor. Brasília (DF): MS; 2009.

Correspondência: Marialda Moreira Christoffel

Prof. Edmundo March, 02, ap.1204

24210-330 - Boa Viagem, Niterói, RJ, Brasil

E-mail: marialdanit@gmail.com 